\title{
PROGRAMA DE EXTENSÃO SINESTÉSICOS: ARTE, CULTURA \& COMPORTAMENTOS ALTISSONANTES
}

Originais recebidos em: 23/07/2011

Aceito para publicação em: 13/02/2012

\section{Atilio Butturi Bunior}

Universidade Federal da Fronteira Sul

a butri@yahoo.com.br

Ani Carla Marchesan

Universidade Federal da Fronteira Sul animarchesan@gmail.com

Pedro Paulo Venzon Filho

pedro.venzon@hotmail.com

Universidade Federal da Fronteira Sul

\section{Resumo}

Este artigo apresenta o Programa Sinestésicos: arte, cultura \& comportamentos altissonantes, desenvolvido no segundo semestre de 2010, na Universidade Federal da Fronteira Sul, campus Erechim. Descreve o Programa e seus quatro projetos: Cinema e Saber, Literatura e Discurso, Diálogos, e Festival Intermitente de Bandas. O objetivo do Programa era a formação de público para manifestações artísticoculturais. Percebeu-se, com o desenvolvimento do Sinestésicos, que é de fundamental importância a criação de repertório estético e cultural e a problematização de categorias como "popular" e "erudito". Conclui-se que o Programa foi capaz de atingir seus objetivos iniciais e fomentar a preocupação com arte e cultura na universidade e na comunidade participante.

Palavras-chave: Discurso artístico. Cultura. Formação de público.

\section{EXTENSION PROGRAM SINESTÉSICOS (SYNESTHESIA): ART, CULTURE \& RESOUNDING BEHAVIOR}

\begin{abstract}
This article presents the program Sinestésicos (Synesthesia): art, culture \& resounding behavior, developed in the second half of 2010 at the Federal University of Southern Frontier, Campus Erechim. Describes the Program and its four projects, Knowing and Cinema, Literature and Discourse, Dialogue and Flashing Band Festival, whose aim was to generate public interest for artistic and cultural expressions. It was noticed, with the development of Sinestésicos, which is of fundamental importance to the creation of aesthetic and cultural repertoire and problematize categories such as "popular" and "scholar". It is concluded that the program was able to achieve its initial goals and foster a concern with art and culture at the University and community participant.
\end{abstract}

Keywords: Art discourse. Culture. Education of the public. 


\section{INTRODUÇÃO}

Este artigo pretende descrever o Programa Sinestésicos: arte, cultura \& comportamentos altissonantes, criado em 2010, na Universidade Federal da Fronteira Sul, campus Erechim, a partir da necessidade de ampliar o escopo de atuação da universidade e da tentativa de trazer à tona a diversidade dos saberes que circulam em seu entorno e em seu contexto cultural amplo. O Sinestésicos foi criado como Programa de Extensão para que, num só golpe, apresentasse a discussão acadêmica à comunidade e permitisse a circulação dos saberes ditos "leigos" no interior da academia, de modo a problematizar tanto os saberes quanto sua relação com a alteridade.

O objetivo geral era estabelecer um ciclo de atividades acadêmicas, com periodicidade regular e ênfase em manifestações artístico-culturais, a fim de incentivar a circulação de informações, saberes e práticas entre a universidade e a comunidade erechinense. Buscava-se formar público proficiente e oferecer, de modo constante, o acesso ao capital cultural, com ênfase nas atividades artístico-culturais, a fim de fomentar a autonomia artístico-cultural local e a implementação de programas definitivos que contemplassem as demandas da comunidade acadêmica em relação aos eixos temáticos propostos.

O Sinestésicos foi desenvolvido em quatro projetos de extensão ${ }^{1}$, denominados eixos, a saber: EIXO DIÁLOGOS, cujo objetivo era a amplificação das problemáticas acadêmicas, na empresa de entabular uma aproximação com os discursos exteriores à academia, trazendo à tona diferentes pontos de vista acerca de questões relevantes na contemporaneidade; EIXO LITERATURA - Literatura e discurso, cujo objetivo foi a formação de um público leitor que dominasse as estratégias discursivas do campo literário, tanto na modalidade da fruição estética quanto na da relação da literatura com a exterioridade; EIXO MÚSICA - Festival Intermitente de Música, que tinha como objetivo a socialização da produção musical da região, sobretudo aquela não contemplada nas políticas públicas tradicionais; EIXO CINEMA - Cinema e Saber, que pretendeu socializar saberes acerca da temática em debate e estabelecer com o público uma relação dialética, fazendo do cinema um instrumento para a construção de pontes entre saberes diversos em uma relação enriquecedora para todas as partes.

A fim de inteligir uma caracterização do discurso artístico-cultural, foram tomadas, como ponto de partida, as discussões acerca da pós-modernidade (LYOTARD, 1998) e a

\footnotetext{
${ }^{1}$ O Programa teve coordenação dos professores Atílio Butturi Junior, Ani Carla Marchesan, Gerson Wasen Fraga e Paulo José Sá Bittencourt, da Universidade Federal da Fronteira Sul.

Extensio: R. Eletr. de Extensão, ISSN 1807-0221 Florianópolis, Ano 8, n. 12, p. 91-99, 2011. 
avaliação do discurso artístico como um dos discursos culturais e não mais aquele que permite o acesso privilegiado a qualquer noumenon. No caso desse discurso artístico, a revisão primeira é a da autorreferencialidade, questão formalista que até o período áureo do estruturalismo autotélico esteve vinculada a toda sorte de pesquisas e discussões. Isso posto, se considerarmos a questão ontológica que institui a Arte, é preciso que se passe a entendê-la como uma linguagem e, mais que isso, um discurso artístico - a letra minúscula corrobora mesmo a metamorfose.

Além disso, partiu-se de uma concepção discursiva de leitura do artefato artísticocultural, ancorada num criticismo sempre atento às condições de produção e circulação dos sentidos. O Programa, então, buscou oferecer o contato com manifestações artístico-culturais contemporâneas, a fim de garantir uma incipiente proficiência discursiva em cada uma das modalidades apresentadas: cinema, literatura, música e diálogos.

Para isso, foi utilizado o conceito de campo (BOURDIEU, 2004), entendendo-o enquanto célula do universo discursivo de relativa autonomia e que carrega em si relações constitutivas com as exterioridades. Tal alicerce teórico faz-nos observar tanto características formais relevantes quanto nos permite relacionar a forma com o contexto no qual pode ser produzida.

A intenção seria, pois, auxiliar na construção de uma chave discursiva que permitisse aos alunos um olhar menos ingênuo diante dos artefatos culturais; sabendo, então, que os sentidos são móveis, porém circunscritos a "regimes" de dizer, intentaremos engendrar o saber sobre cada um dos campos que permita uma melhor fruição do artístico.

Além disso, acreditava-se que democratizar o acesso aos artefatos de uma cultura dita "de elite" seria oferecê-la, em suas mais diversas modalidades, àqueles que dela estavam excluídos. No caso dos eixos temáticos escolhidos, a diversidade contribuiria tanto para o desenvolvimento metadiscursivo quanto para uma aproximação de discursos culturais dos quais a comunidade permanece alienada, seja por sua condição socioeconômica, seja pela falta de iniciativa do ensino formal. Sob tal aspecto, a empresa era dotar os sujeitos de capital cultural, com vistas não apenas à formação de público, mas de trabalho de produção e de problematização de seus universos simbólicos.

Partiu-se, sobretudo, de uma leitura das concepções de cultura dos documentos oficiais internacionais, cuja base reside nos textos urdidos pela Unesco a partir da década de setenta. Assim, primeiramente, observa-se a necessidade de apontar a cultura como peça-chave e independente do desenvolvimento das nações. Depois, a partir de 2005, com a Declaração 
Universal sobre a Diversidade Cultural, amplia-se o papel da cultura como artífice fundamental do desenvolvimento e da democracia. Nesse segundo caso, a correlação entre cultura e democracia revela a valorização da diversidade e pela tentativa de amalgamar a autonomia artística e cultural localistas, tendo em vista um conceito mais amplo de cultura, relacionado à política, economia e emancipação dos sujeitos (PITOMBO, 2007).

É da perspectiva de criação de uma autonomia cultural que se empenha o Sinestésicos, ao estabelecer o imperativo da assunção de repertórios diversos com vistas à produção autônoma de artefatos de cultura.

\section{MATERIAL E MÉTODOS}

Conforme exposto, a intenção do Sinestésicos era auxiliar na construção de um olhar menos ingênuo diante dos artefatos culturais; sabendo, então, que os sentidos são móveis, porém circunscritos a "regimes" de dizer, intentar-se-ia engendrar o saber sobre cada um dos campos que permitisse uma melhor fruição do artístico.

Para que isso fosse possível, quatro projetos foram criados e desenvolvidos simultaneamente. A participação em cada atividade era aberta a toda comunidade, sendo que as inscrições poderiam ser realizadas no local. A divulgação se deu na forma de cartazes, via imprensa e através do blog (http://sinestesicosuffs.blogspot.com) e do twitter (http://twitter.com/\#!/Sinestesicos).

Figura 1: cartaz de divulgação do Programa Sinestésicos — primeira etapa

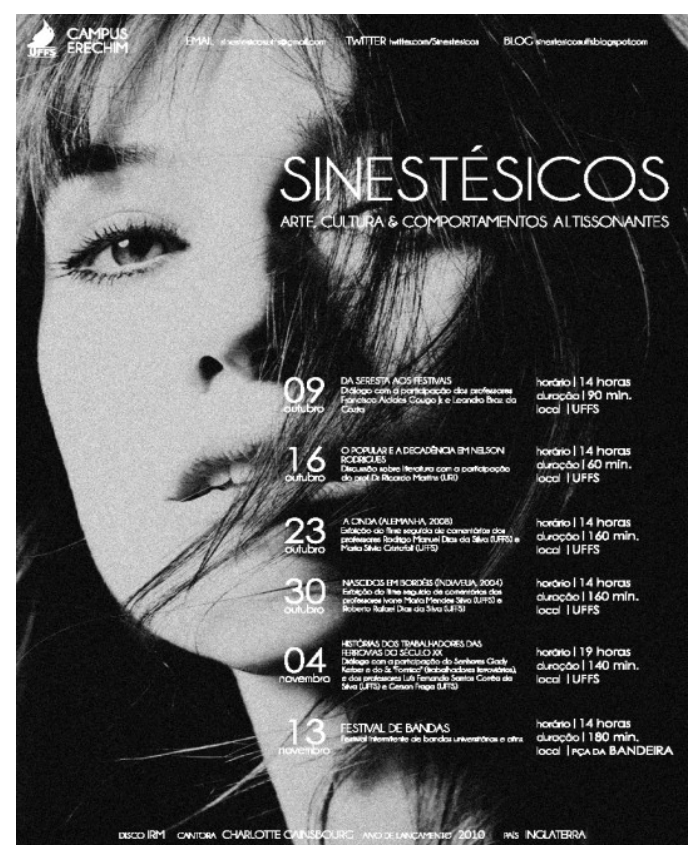

Extensio: R. Eletr. de Extensão, ISSN 1807-0221 Florianópolis, Ano 8, n. 12, p. 91-99, 2011. 
Fonte: arquivo pessoal.

O público estimado foi de 900 pessoas no total, com média de cerca de 75 participantes por evento. Os projetos estavam assim divididos em sua realização:

- Cinema e Saber - as atividades desse projeto foram realizadas nos dias 23/10/10, 30/10/10, e 18/12/10, nos quais foram exibidos os filmes: A onda, Nascidos em Bordéis e Star trek, respectivamente. Os filmes foram seguidos de discussão acadêmica variada, e obteve-se público cativo, sobretudo se pensarmos que se tratava de cinema "não comercial". Os debates foram conduzidos por vários professores da UFFS, e a exibição foi possível via parceria com a Prefeitura Municipal de Erechim.

Figura 2: 23/10/10 - Exibição do filme $A$ onda.

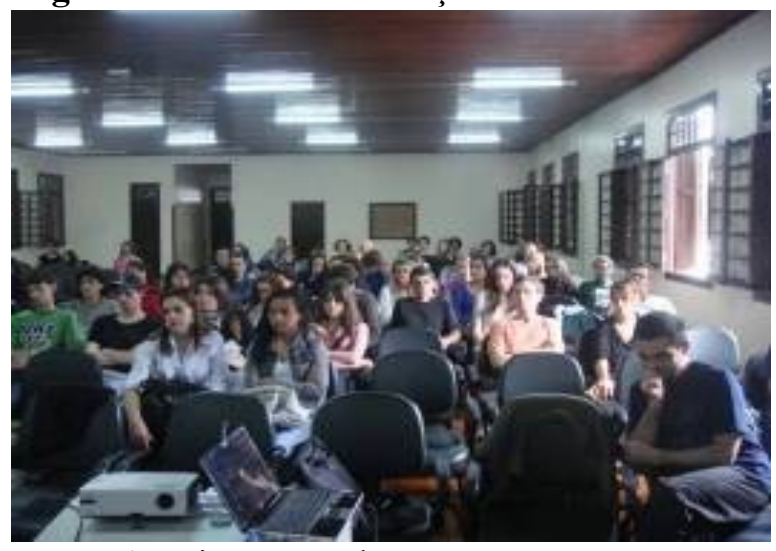

Fonte: Arquivo pessoal.

- Diálogos - esse projeto ocorreu entre setembro e dezembro de 2010 e contou com três palestras/debates: Da seresta aos festivais; História dos trabalhadores das ferrovias do século XX e Rock, história e outros lances. Nesse projeto, a participação de leigos e acadêmicos se deu de forma ímpar. Os encontros proporcionaram, entre outras coisas: discussão sobre cultura popular e sua valoração, via discurso musical; debate sobre o papel da arte e da cultura; interação da plateia com os debatedores; reflexão sobre a própria cultura local; discussão e relatos sobre a história dos trabalhadores operários do séc. XX e sua relação com o progresso econômico das cidades; diferentes visões a respeito da história do rock: uma visão mais acadêmica, uma abordagem prática e uma visão de um jovem erechinense. 
Figura 3: 4/12/10 - Debate: Roque, história e outros lances.

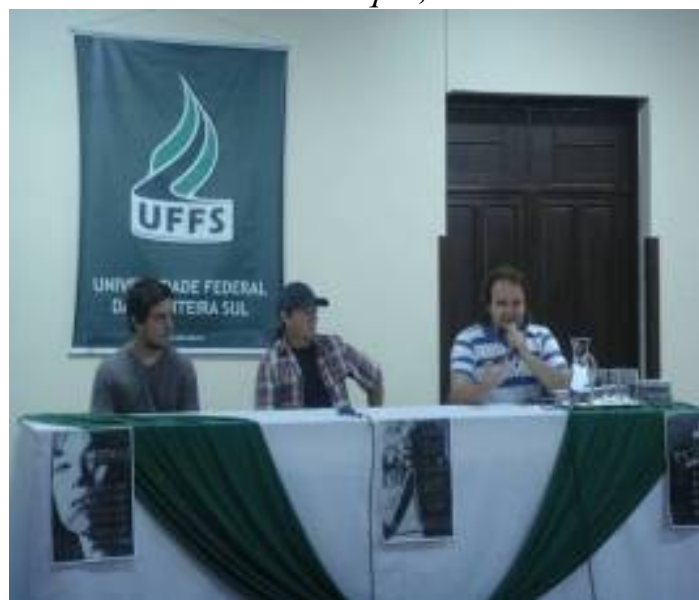

Fonte: Arquivo pessoal

- Festival Intermitente de Bandas - esse projeto teria duas edições, mas apenas uma foi possível por problemas "climáticos". Foram mais de 15 bandas locais inscritas, sobretudo da cena "rocker" local. Novamente, o Sinestésicos contou com o apoio da Prefeitura Municipal de Erechim, que disponibilizou som de alta qualidade e o espaço da Praça Jayme Lago para as duas apresentações de bandas. Além disso, inseriu-se no projeto a apresentação de um recital feito pela Escola Municipal de Belas Artes Osvaldo Engel, no dia 27/11/10.

Figura 4: 13/11/10 - Festival intermitente de música.

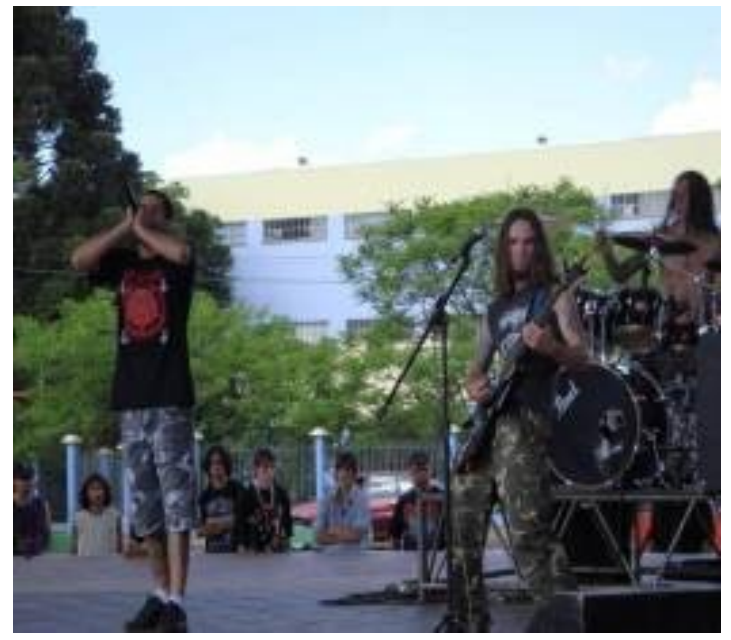

Fonte: Arquivo pessoal

- Literatura e Discurso - nesse projeto foram organizadas duas palestras. A primeira, do professor Ricardo Martins, versava sobre a obra de Nelson Rodrigues. A segunda, do escritor Miguel Sanches Neto, foi focada na produção literária e na função de autor. 
Figura 5: 16/10/10 - Palestra com Ricardo Martins.

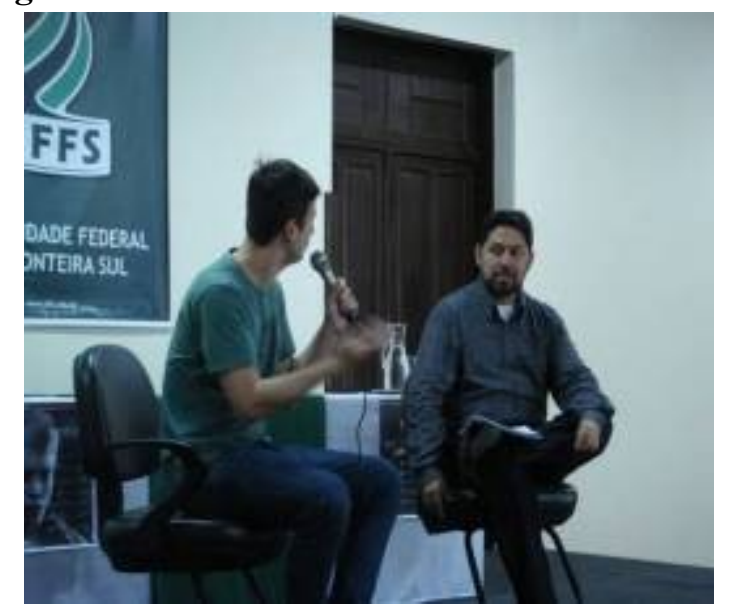

Fonte: Arquivo pessoal

\section{RESULTADOS E ANÁLISE}

O Programa Sinestésicos foi criado como iniciativa piloto de extensão, na Universidade Federal da Fronteira Sul, que teve as atividades iniciadas em março de 2010 e o Sinestésicos como seu primeiro programa institucional.

Não obstante à dificuldade de identificação das necessidades locais, o Programa teve sucesso tanto internamente quanto junto à ampla comunidade da região de Erechim. Com público de mais de 900 pessoas em suas 12 atividades (média de mais de 70) e mais de 6.500 acessos, durante três meses, em seu blog, a iniciativa deu visibilidade à então incipiente universidade e garantiu o primeiro acesso ao discurso artístico para muitos dos sujeitos envolvidos.

Se pensarmos em cada um dos projetos em separado, é mister indicar que, com o Projeto Diálogos, foi possível verificar o quão importante podem ser o saber dito "leigo" e a participação da comunidade externa, dada a acolhida positiva aos palestrantes da comunidade externa. Já o Festival Intermitente de Música permitiu a divulgação das bandas locais e trouxe efetiva participação da comunidade externa, além de permitir novas relações com artistas locais e contatos para futuras apresentações.

No caso do Projeto Literatura e Discurso, os convidados trouxeram aos acadêmicos e ao público presente a possibilidade de um contato direto com a literatura e as reflexões pertinentes a seu campo. Contamos, inclusive, com a participação do crítico e literato Miguel Sanches Neto, cuja fala permitiu uma aproximação direta entre sujeitos e circuito do livro. 
Finalmente, o projeto Cinema e Saber foi capaz de oferecer alternativas de lazer distantes do cinema de entretenimento e soube refletir acerca de variadas temáticas que tangenciam a discussão fílmica e os saberes da universidade.

Além disso, é importante ressaltar que, em avaliação posterior à execução do Programa, realizada via questionário com os espectadores e outros participantes, os resultados apontaram cerca de $90 \%$ de resultados positivo — numa escala de avaliação dos itens, divididos desde o material gráfico até o conteúdo, que variava entre muito bom, bom, regular e ruim.

Fundamentalmente, o que se pretendeu com o Sinestésicos foi iniciar um processo de criação da cidadania cultural (RUBIM, 2007), buscando relacionar diversidade cultural e política cultural, com o objetivo de democratização da fruição e da produção dos artefatos artístico-culturais no sentido de ampliação do poder dos sujeitos, em âmbito local e global.

Assim, ao estabelecer como prioridade o desenvolvimento do capital cultural, o Programa entende o papel da UFFS como ator cultural vinculado ao Estado, mas preocupado em transcender as esferas autoritárias e populistas que caracterizavam, de acordo com Chaú (1995), as iniciativas de caráter público no âmbito da cultura do Brasil. Pretendeu-se, portanto, ultrapassar o que a autora chama de "estadismo cultural", através de iniciativas de estímulo da criação e da fruição, trazendo o entendimento de cultura como direito inalienável dos sujeitos.

Dessa perspectiva do direito, novamente a cultura está vinculada à cidadania, entendida como participação mais efetiva dos sujeitos na produção e na acumulação do capital simbólico, buscando uma democratização efetiva das práticas artístico-culturais, inferidas como discurso e, portanto, sempre marcadas por condições específicas de existência política e social.

Ademais, o circuito da cultura também necessita, para uma efetiva democratização, de acordo com Rubim (2007), de um itinerário de fruição e informação pública dos eventos. Nessa esteira, é relevante também ressaltar o papel do Sinestésicos na divulgação da Universidade Federal da Fronteira Sul como promotora de manifestações artístico-culturais. Em 2010, a universidade estava em seu primeiro ano de funcionamento. O Programa obteve público variado e grande exposição na imprensa local, com mais de quarenta matérias, divididas entre mídia eletrônica (jornais online, blogs) e tradicional (jornais da cidade de Erechim e região), o que permitiu a visibilidade da instituição como elemento importante no circuito de criação e divulgação local da arte e da cultura. 


\section{CONSIDERAÇÕES FINAIS}

Finalizado o Sinestésicos, é possível concluir que, não obstante sua característica de projeto-piloto para a realização de programas efetivos na UFFS - campus Erechim - o Sinestésicos obteve pleno sucesso na realização de seus objetivos, tanto na iniciativa de formar público proficiente quanto em sua capacidade de fomentar a discussão cultural na comunidade - acadêmica ou não.

Certamente, as dificuldades com relação às verbas para os eventos e à manutenção do público são tópicos a se discutir; todavia, a experiência permitiu traçar um perfil geral das demandas da região e do papel que a universidade, com sua força catalisadora, terá no desenvolvimento artístico-cultural da região (cultural ou geográfica) em que está inserida.

\section{REFERÊNCIAS}

BOURDIEU, P. As regras da arte: gênese e estrutura do campo literário. 2. ed. São Paulo:

Companhia das Letras, 2004.

CHAUÍ, M. Cultura política e política cultural. Estudos Avançados, São Paulo, v.9,. n. 23, jan./abr. 1995.

LYOTARD, J. F. A condição pós-moderna. .ed. Rio de Janeiro: José Olympio, 1998.

PITOMBO, M. Entre o universal e o heterogêneo: uma leitura do conceito de cultura na UNESCO. In: NUSSBAUMER, G. M. (Org.). Teorias e políticas da cultura: visões multidisciplinares. Salvador: EDUFBA, p.115-138.

RUBIM, A. A. C. Políticas culturais: entre o possível e o impossível. In: NUSSBAUMER, G. M. (Org.). Teorias e políticas da cultura: visões multidisciplinares. Salvador: EDUFBA, p.139-158. 